\title{
Nonatopic asthma is associated with helminth infections and bronchiolitis
} in poor children

\author{
M.U. Pereira*, P.D. Sly", , P.M. Pitrez*, M.H. Jones*, D. Escouto*, A.C.O. Dias*, \\ S.K. Weiland ${ }^{+}$and R.T. Stein*
}

ABSTRACT: Asthma is common in urban centres in Latin America, but atopic asthma may not be the main phenotype among children. Helminth infections are highly prevalent in poor populations, and it was hypothesised that they attenuate allergic asthma, whereas other factors are related to the expression of a nonatopic wheeze/asthma phenotype.

A total of 1,982 children from Southern Brazil with a mean \pm SD age of $10.1 \pm 0.76$ yrs completed asthma questionnaires, and 1,011 were evaluated for intestinal parasites and atopy using skinprick tests (SPTs).

Wheeze in the previous 12 months was reported by $25.6 \%$, and $9.3 \%$ showed current asthma; $13 \%$ were SPT-positive and $19.1 \%$ were positive for any helminths. Most children with either wheeze or asthma were SPT-negative; however, severe wheeze was more prevalent among the atopic minority. Helminth infections were inversely associated with positive SPT results. Bronchiolitis before the age of 2 yrs was the major independent risk factor for asthma at age $10 \mathrm{yrs}$; high-load Ascaris infection, a family history of asthma and positive SPT results were also asthma risk factors.

Most asthma and wheeze are of the nonatopic phenotype, suggesting that some helminths may exert an attenuating effect on the expression of the atopic portion of the disease, whereas viral bronchiolitis predisposes more specifically to recurrent airway symptoms.

KEYWORDS: Allergy, bronchiolitis, helminths, intestinal parasites, nonatopic asthma, wheeze

$\mathbf{T}$ he increased burden and prevalence of wheeze and asthma since the 1960s are well documented, especially among children living in affluent societies [1]. Asthma in school-age children from developed countries is commonly associated with an atopic phenotype, including bronchial hyperresponsiveness, peripheral blood eosinophilia, increased allergenspecific immunoglobulin (Ig)E levels and positive allergen skin-prick test (SPT) results $[2,3]$. The International Study of Asthma and Allergies in Childhood (ISAAC) has demonstrated that asthma and asthma-related symptoms are highly prevalent among many of the less-privileged communities in Latin America [4]. These data are seemingly at odds with the so-called hygiene hypothesis, and suggest that the relationship between asthma and the atopic phenotype is less clear in children from developing countries. Data from Africa show that the association of asthma with atopy is stronger in children living in urban rather than rural settings [5].
Parasitic infections are common among disadvantaged populations in Africa and Latin America. Recent data from these areas have shown an inverse association between helminth infections and allergy (defined by SPT), and probably an attenuation of asthma-related symptoms $[6,7]$. A series of studies in rural Ecuador have shown that asthma is not common in a highly parasitised population, and that helminth infections are inversely related to allergen skin test reactivity [8]. This raises the question as to which environmental factors might be responsible for the high prevalence of asthma and asthma-related symptoms in nonaffluent populations in Latin America [9].

In the present study, a population of school-age children from a poor urban community in Southern Brazil, where helminth infections are common, was evaluated. The impact of parasite load and other environmental exposures on asthma and asthma-related symptoms at age 10 yrs was determined. It was hypothesised that

\section{AFFILIATIONS}

*Paediatric Pulmonary Research Laboratory, Biomedical Research Institute, Pontifical Catholic University of Rio Grande do Sul Porto Alegre, Brazil.

\#World Health Organization Collaborating Centre for Research on Children's Environmental Health,

Curtin University of Technology, and "Centre for Child Health Research, University of Western Australia, Perth, Australia.

${ }^{+}$Dept of Epidemiology, University of UIm, UIm, Germany.

\section{CORRESPONDENCE}

R.T. Stein

Av. Ipiranga 6690

conj. 420 - Laboratório de Pediatria IPB-PUCRS

Porto Alegre

RS - CEP 90610-000

Brazil

Fax: 555133845104

E-mail: rstein@pucrs.br

Received:

October 012006

Accepted after revision:

February 112007

SUPPORT STATEMENT

This study was supported by a grant from the Rudolph and Clothilde

Ebehardt Stiftung, UIm, Germany.

STATEMENT OF INTEREST

None declared. 
asthma and asthma-related symptoms were common among these children living in a pro-inflammatory urban environment, and that helminth infections would attenuate the role of atopy in driving asthma in these children.

\section{METHODS}

As part of the ISAAC Phase II study, a sample of 2,058 schoolchildren aged 9-13 yrs were randomly chosen from a total of 3,049 children enrolled in the fourth and fifth middleschool levels of the public system of a small town, Uruguaiana, in the extreme South of Brazil. Parents were interviewed at home by trained research interviewers and completed the basic questionnaire of the ISAAC Phase II protocol along with some extra questions. The main issues under investigation were personal and familial risk factors for asthma, as well as environmental and lifestyle variables. The main outcome variables were current wheeze ("wheeze in the past 12 months") and active asthma ("wheeze in the past 12 months" plus "asthma ever"). Severe asthma was defined as four or more acute attacks in the previous 12 months. Children were classified as having had bronchiolitis when mothers or carers answered positively to the question "Was your child admitted to a hospital or seen in an emergency room with bronchiolitis before the age of two years?" Variables such as born before term (i.e. "Was your child born before term?"), normal birthweight $(\geqslant 2,500 \mathrm{~g})$, maternal smoking (current and during pregnancy), number of siblings, humidity in the home, current maternal smoking (not a quantitative variable) and exclusive breastfeeding for $\geqslant 6$ months were defined as in the ISAAC Phase II core protocol [10]. Living in a poor neighbourhood, a marker of living standard, was classified using the response "the family lived in a suburban area with few parks and gardens".

A random sample of these children $(n=1,200)$ was selected to provide stool samples for the determination of intestinal parasitic infections. Three stool samples were collected from the children on different days during home visits, with specimens rapidly transported to and processed in the laboratory. Each stool sample was analysed using three methods: 1) the method of RITCHIE et al. [11] for the detection of helminth ova and protozoan cysts and oocysts; 2) the method of BAERMAN [12] for the identification of Strongyloides stercoralis larvae; and 3) the Kato-Katz method for quantitative evaluation of helminth ova [13]. A subject was considered infected if positive results were obtained in any of the tests for specific parasites. High quantitative counts based on the KatoKatz method were defined as those egg counts falling within the upper tertile of the distribution (which corresponded to $\geqslant 100 \mathrm{eggs} \cdot \mathrm{g}^{-1}$; called high-load) for any helminth or for specifically Ascaris lumbricoides (Ascaris) infections.

The same subsample of children was also skin tested using relevant aeroallergens (Dermatophagoides pteronyssinus, D. farinae, cat dander, mix of grasses, mix of trees and Alternaria alternata, plus positive and negative controls) according to the protocol used in the ISAAC Phase II study (ALK-Abelló, Madrid, Spain) [10, 14]. All SPTs were performed in the schools by a single trained researcher. A subject was defined as atopic according to the ISAAC protocol, i.e. a mean weal diameter of $\geqslant 3 \mathrm{~mm}$ greater than the negative control for at least one allergen.

\section{Statistical analyses}

Univariate and multivariate logistic regression models were used to calculate adjusted and unadjusted odds ratios (OR) and $95 \%$ confidence intervals (CI) for the main outcome variables (current wheeze, active asthma and SPT results). Risk factors known to be associated with wheeze and asthma, and those significantly associated with these outcomes in the bivariate analyses, were included in the multivariate models, which were always adjusted for age and sex.

The present study was approved by the Human Ethics Committee of the Pontifical Catholic University of Rio Grande do Sul, Porto Alegre, Brazil.

\section{RESULTS}

The city of Uruguaiana has a population of $\sim 130,000$; its major economic activity relates to agriculture, with a small portion of the population working in the fields and most in servicerelated jobs in the town. Most of the population is not served by a sewage system, and there are high rates of unemployment and underemployment. Questionnaires were completed for $96.3 \%(1,982$ out of 2,058$)$ of the ISAAC Phase II sample of children. SPTs were completed in all but one of the target subsample of 1,200, and three stool samples were collected from $87.8 \%(1,054$ out of 1,200$)$. A total of 1,011 subjects provided complete data for parasite analysis, SPTs and ISAAC Phase II questionnaires. This subsample was broadly representative of the entire cohort, with no differences between the two samples, except that there were fewer mothers with $<8$ yrs of formal education and fewer families living in a poor neighbourhood in the subgroup (table 1 ). The mean \pm SD age at the time of the survey was $10.1 \pm 0.76$ yrs for both the complete cohort and the subsample, with a range of $8.2-13.3$ yrs. The results presented here are restricted to the 1,011 children for whom complete data are available.

\section{Demographic data}

The children were breastfed for $\geqslant 6$ months, and one tenth of the population was born before term. Approximately one third of mothers smoked either during their children's first year of life or at the time of the year 10 survey; $22 \%$ smoked during pregnancy. Mothers were schooled for $6.6 \pm 2.9 \mathrm{yrs}$, with most reporting $<8$ yrs of formal education (table 1). Children had, on average, $2.7 \pm 2.0$ siblings, with a third of the subjects having no siblings; $>90 \%$ lived in a poor neighbourhood and half of the households were reported as being humid.

Wheeze in the previous 12 months was present in a quarter of the children and $9.2 \%$ were reported to have active asthma (table 1). Severe asthma was reported in 6.9\%, 5.8\% exhibited acute exacerbations severe enough to limit speech and $17.3 \%$ showed wheeze after exercising. Hospital admission or emergency room attendance for bronchiolitis before the age of 2 yrs was reported for $6.3 \%$ of the children (table 1 ). The maternal and paternal history of asthma was positive for $<10 \%$ of the children.

Of the children, $13 \%$ were atopic; the most prevalent sensitisation was that to D. pteronyssinus $(11.2 \%)$, followed by D. farinae $(6.6 \%)$. Very few $(3.6 \%)$ were SPT-positive for the other four allergens tested (cat dander, Alternaria, and grass and tree mixes). 


\begin{tabular}{|c|c|c|c|}
\hline \multirow[t]{2}{*}{ TABLE 1} & \multicolumn{3}{|c|}{$\begin{array}{l}\text { Demographic characteristics of the } \\
\text { questionnaire-only sample and the subsample of } \\
\text { children with completed questionnaires, stool } \\
\text { samples for parasitological tests and skin-prick } \\
\text { tests }\end{array}$} \\
\hline & & Questionnaire only ${ }^{\#}$ & Subsample \\
\hline \multicolumn{2}{|l|}{ Subjects $n$} & 1982 & 1011 \\
\hline \multicolumn{2}{|l|}{ Male sex } & $993(50.1)$ & $495(49.0)$ \\
\hline \multicolumn{2}{|c|}{ Birthweight $\geqslant 2500 \mathrm{~g}$} & $1736(90.4)$ & $865(88.6)$ \\
\hline \multicolumn{2}{|c|}{ Born before term } & $189(9.9)$ & $93(9.6)$ \\
\hline \multicolumn{2}{|c|}{ Breastfeeding $\geqslant 6$ months } & $1705(86.0)$ & $852(84.7)$ \\
\hline \multicolumn{2}{|c|}{ Current maternal smoking } & $624(31.5)$ & $322(31.9)$ \\
\hline \multicolumn{2}{|c|}{ Maternal schooling $\geqslant 8 \mathrm{yrs}$} & $481(24.3)$ & $195(19.3)^{+}$ \\
\hline \multicolumn{2}{|l|}{$\geqslant 1$ sibling } & $1373(69.3)$ & $730(72.2)$ \\
\hline \multicolumn{2}{|c|}{ Humid household } & $893(45.1)$ & $474(46.9)$ \\
\hline \multicolumn{2}{|c|}{ Poor neighbourhood } & $1777(99.7)$ & $956(94.7)^{+}$ \\
\hline \multicolumn{2}{|c|}{ Maternal asthma } & $149(7.5)$ & $78(7.7)$ \\
\hline \multicolumn{2}{|c|}{ Paternal asthma } & $108(5.5)$ & $58(5.8)$ \\
\hline \multicolumn{2}{|c|}{ Wheeze in past 12 months } & $510(25.6)$ & $273(27.0)$ \\
\hline \multicolumn{2}{|c|}{ Active asthma } & $184(9.3)$ & $93(9.2)$ \\
\hline \multicolumn{2}{|l|}{ Atopy } & NA & $131(13.0)$ \\
\hline \multicolumn{2}{|c|}{ Bronchiolitis aged $<2$ yrs } & $136(6.9)$ & $63(6.3)$ \\
\hline \multicolumn{2}{|c|}{ Severe asthma } & $130(6.6)$ & $70(6.9)$ \\
\hline
\end{tabular}

Data are presented as $n$ or $n(\%)$. Denominators for the variables may differ slightly due to missing values. NA: not available. ${ }^{\#}$ : International Study of Asthma and Allergies in Childhood Phase II questionnaire; ": $\geqslant 4$ attacks; $+: p \leqslant 0.01$

\section{Infection with intestinal parasites}

Almost $20 \%$ of the children were infected by helminths, with Giardia lamblia and Ascaris lumbricoides being the most common parasite recovered in the stool samples (table 2 ); $\sim 10 \%$ of children were infected with multiple parasites, e.g. $5.4 \%$ of the Ascaris-infected children were also infected with Giardia.

\section{Associations with wheeze and asthma}

The vast majority (216 out of $273 ; 79 \%$ ) of the children with current wheeze were not atopic, with only 57 giving any positive SPT results. Similarly, the majority (65 out of 93; 70\%) of those with active asthma were nonatopic. However, atopic children with current asthma were more likely to show more severe disease (OR 2.6, 95\% CI 1.04-6.4) than nonatopic asthmatics. Similar findings were also observed for SPTpositive current wheeze. Despite the fact that the majority of asthmatics were not atopic, being atopic was a significant risk factor for both current wheeze (OR 2.4, 95\% CI 1.6-3.5) and active asthma (OR 3.4, 95\% CI 2.1-5.5) in the total study group.

Most (24 out of $25 ; 96.0 \%$ ) of the children with high-load helminths and wheezing at age 10 yrs were SPT-negative. Children with high-load Ascaris or high-load (any) helminths were more likely to show wheeze or active asthma at age 10 yrs compared with both those with a lower load and no helminths (table 3). Nonatopic wheezers were almost four times more likely (OR 3.9, 95\% CI 1.3-11.3) to exhibit helminth infections ( 49 out of $216 ; 22.7 \%$ ) than atopic wheezers (four out

\begin{tabular}{|c|c|c|}
\hline \multirow[t]{2}{*}{ TABLE 2} & \multicolumn{2}{|c|}{$\begin{array}{l}\text { Frequencies of different intestinal parasite } \\
\text { species found in faecal samples }{ }^{\#}\end{array}$} \\
\hline & & Frequency \\
\hline \multicolumn{2}{|c|}{ No helminths } & $853(80.9)$ \\
\hline \multicolumn{2}{|c|}{ Any helminths } & $201(19.1)$ \\
\hline \multicolumn{2}{|c|}{ Ascaris lumbricoides } & $130(12.3)$ \\
\hline \multicolumn{2}{|c|}{ Trichurus trichiura } & $57(5.4)$ \\
\hline \multicolumn{2}{|c|}{ Hymenolepis nana } & $27(2.6)$ \\
\hline \multicolumn{2}{|c|}{ Enterobius vermicularis } & $12(1.1)$ \\
\hline \multicolumn{2}{|c|}{ Taenia solium } & $8(0.8)$ \\
\hline \multicolumn{2}{|c|}{ Strongyloides stercoralis } & $3(0.3)$ \\
\hline \multicolumn{2}{|c|}{ Entamoeba hystolytica } & $74(7.0)$ \\
\hline \multicolumn{2}{|c|}{ Giardia Iamblia } & $105(10.0)$ \\
\hline \multicolumn{2}{|c|}{ High-load helminths } & $70(6.6)$ \\
\hline \multicolumn{2}{|c|}{ High-load ${ }^{\circ}$ Ascaris } & $58(5.5)$ \\
\hline \multicolumn{3}{|c|}{$\begin{array}{l}\text { Data are presented as } n(\%){ }^{\#} \text { : positive identification of parasites in any of three } \\
\text { stool samples examined using three different laboratory techniques (see } \\
\text { Methods section); }{ }^{\bullet}: \geqslant 100 \text { eggs } \cdot \mathrm{g}^{-1} \text {. }\end{array}$} \\
\hline
\end{tabular}

of $57 ; 7 \%)$.This risk was even greater for nonatopic wheezers with high-load helminths and high-load Ascaris infections.

Children with bronchiolitis seen in hospital before the age of 2 yrs were at high risk of wheezing later in life and were 12 times more likely to show active asthma at the age of $10 \mathrm{yrs}$ (table 3). There was a synergistic interaction between bronchiolitis before the age of 2 yrs and helminth infection at $10 \mathrm{yrs}$, increasing the risk of active asthma at the age of $10 \mathrm{yrs}>40$ fold (OR 42.7, 95\% CI 11.4-160.5). Children with bronchiolitis in early life were no more likely to be SPT-positive than those who did not have bronchiolitis.

Children living in humid households were significantly more likely to exhibit current wheeze and active asthma. Maternal smoking was also a risk factor for both current wheeze and active asthma (table 3). Paternal asthma was significantly associated with wheeze (OR 5.0, 95\% CI 2.9-8.6) and asthma (OR 5.2, 95\% CI 2.9-9.5), as was maternal asthma (table 3).

\section{Risk factors for atopy}

The minority of children with better educated mothers ( $>8$ yrs of schooling) were more likely to be atopic (OR 1.8, 95\% CI 1.22.7) than those with less maternal schooling. Other risk factors for positive SPT results on bivariate analyses were current wheeze (OR 2.4, 95\% CI 1.6-3.5; p<0.001) and active asthma (OR 3.4, 95\% CI 2.1-5.5; $\mathrm{p}<0.001$ ); whereas infection with any parasite (OR $0.6,95 \%$ CI $0.4-0.9 ; \mathrm{p}<0.01$ ) or any helminth (OR $0.4,95 \%$ CI $0.2-0.8 ; \mathrm{p}<0.01)$ and a higher infective load of helminth (OR 0.3, 95\% CI 0.09-0.94; $\mathrm{p}<0.05$ ) were protective. A similar trend was seen for high-load Ascaris (OR 0.4, 95\% CI $0.1-1.2$ ) and living in a poor neighbourhood (OR $0.7,95 \% \mathrm{CI}$ $0.3-1.5)$, but these did not reach significance. On average, atopic children had significantly fewer siblings $(2.35 \pm 1.70$ versus $2.90 \pm 2.17 ; \mathrm{p}<0.01$ ) than nonatopic children.

\section{Multivariate logistic regression analyses}

After adjusting for age and sex, the strongest independent risk factor for active asthma and current wheeze was bronchiolitis 
TABLE 3 Bivariate analyses of various risk factors and the main outcome variables of wheeze ${ }^{\#}$ and asthma" at age 10 yrs

\begin{tabular}{|c|c|c|c|c|c|}
\hline & \multirow[t]{2}{*}{ Subjects with risk factor $n$} & \multicolumn{2}{|c|}{ Wheeze } & \multicolumn{2}{|c|}{ Asthma } \\
\hline & & n (\%) & OR $(95 \% \mathrm{Cl})$ & $n(\%)$ & OR $(95 \% \mathrm{Cl})$ \\
\hline Maternal schooling $\geqslant 8 \mathrm{yrs}$ & $195 / 1011$ & $43(22.1)$ & $0.7(0.5-1.4)$ & $11(5.5)$ & $0.5(0.3-1.0)$ \\
\hline Born before term & 93/970 & 30 (32.3) & $1.3(0.8-2.1)$ & $8(8.6)$ & $0.9(0.4-1.9)$ \\
\hline Maternal smoking & $322 / 1009$ & $104(32.3)$ & $1.5(1.1-2.0)^{\S}$ & $38(11.8)$ & $1.5(1.0-2.4)^{f}$ \\
\hline Poor neighbourhood & $956 / 1009$ & $253(26.5)$ & $0.6(0.3-1.05)$ & $84(8.8)$ & $0.5(0.2-1.0)$ \\
\hline Bronchiolitis aged $<2$ yrs & $159 / 1007$ & $95(59.7)$ & $5.6(4.0-8.0)^{\# \#}$ & $56(35.2)$ & $11.9(7.5-19.0)^{\# \#}$ \\
\hline Any helminths & $195 / 1011$ & $53(27.2)$ & $1.0(0.7-1.4)$ & $20(10.3)$ & $1.2(0.7-1.9)$ \\
\hline High-load $^{+}$helminths & $68 / 1011$ & $25(36.8)$ & $1.6(1.0-2.7)$ & $10(14.7)$ & $1.8(0.9-3.6)$ \\
\hline High-load $^{+}$Ascaris & $56 / 1011$ & $22(39.3)$ & $1.8(1.0-3.0)^{f}$ & $9(16.1)$ & $2.0(0.97-4.2)$ \\
\hline
\end{tabular}

OR: odds ratio; $\mathrm{Cl}$ : confidence interval. ${ }^{*}$ : wheeze in the previous 12 months; ${ }^{\natural}:$ wheeze in the previous 12 months and asthma ever; ${ }^{+}: \geqslant 100$ eggs $\cdot g^{-1} ;{ }^{s}: p \leqslant 0.01$ $f: p \leqslant 0.05 ; \#: p \leqslant 0.001$

before the age of 2 yrs (table 4). A maternal or paternal history of asthma, living in a humid house, positive SPT results and a high Ascaris load (or high load of any helminth) were all risk factors for active asthma (table 4). More years of maternal schooling and having two or more siblings were protective against active asthma. The risk factors for current wheeze at the age of $10 \mathrm{yrs}$ were similar to those for active asthma (table 4); however, high Ascaris load was of borderline significance $(p=0.06)$ for wheeze at age $10 \mathrm{yrs}$ and $>8$ yrs of maternal schooling was borderline and inversely associated with wheeze $(\mathrm{p}=0.06)$.

When multivariate analysis was performed selecting those who were positive for any helminths, children with a history of bronchiolitis were shown to be at even greater risk of active asthma at the age of $10 \mathrm{yrs}$ (OR 68.7, 95\% CI 10.0-470.0; $\mathrm{p}<0.001)$.

\section{Risks for nonatopic wheeze}

Despite the majority of children with wheeze being nonatopic, atopy was a strong risk factor for current wheeze, active asthma and severe wheeze. In order to investigate whether nonatopic asthma might be a different phenotype with different risk factors, the analyses were also performed in the nonatopic population. The association of Ascaris with both current wheeze (OR 11.6, 95\% CI 1.5-86.3) and active asthma (OR 7.4, 95\% CI 0.96-59.4)) was stronger for the nonatopic phenotype than in the general population. The results of multivariate analyses in 829 subjects are shown in table 5. The small number of atopic subjects in the present study does not permit a proper analysis of risk factors among this group. In general, the risk factors for current wheeze and active asthma are similar in the nonatopic and total populations, with the risks due to bronchiolitis aged $<2$ yrs and high-load Ascaris being greater in the nonatopic population.

\section{DISCUSSION}

The aim of the present cross-sectional study was to identify risk factors associated with current wheeze and active asthma in 10-yr-old children from a nonaffluent community in Southern Brazil. The major finding of the present study is that

TABLE 4 Multivariate logistic regression analyses: risk factors associated with wheeze in the previous 12 months and active asthma ${ }^{\#}$

Wheeze OR (95\% Cl)

$$
\begin{gathered}
3.1(1.8-5.3)^{\S} \\
3.9(2.1-7.3)^{\S} \\
5.4(2.9-9.9)^{\S} \\
2.7(1.8-4.1)^{\S} \\
1.5(1.1-2.1)^{f} \\
1.2(0.9-1.7) \\
1.4(0.8-2.3) \\
0.98(0.92-1.0) \\
1.1(0.8-1.5) \\
1.8(0.98-3.4)
\end{gathered}
$$

Active asthma OR $(95 \% \mathrm{Cl})$

$$
\begin{gathered}
5.6(2.8-11.1)^{\S} \\
3.6(1.6-7.9)^{\S} \\
18.1(9.1-36.0)^{\S} \\
6.3(3.4-11.8)^{\S} \\
2.2(1.3-3.8)^{f} \\
1.1(0.6-2.0) \\
0.7(0.3-1.8) \\
0.9(0.8-0.9)^{\# \#} \\
0.5(0.3-0.9)^{\# \#} \\
2.4(1.0-6.1)^{\# \#}
\end{gathered}
$$

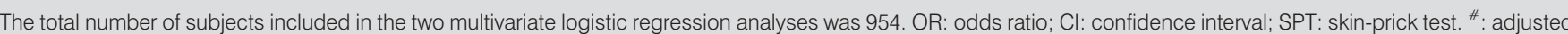
for age and sex; ${ }^{\prime}$ : continuous variable of total duration of maternal schooling used in this specific analysis; ${ }^{+}: \geqslant 100$ eggs $\cdot g^{-1} ; ;^{\varsigma}: p \leqslant 0.001 ;{ }^{f}: p \leqslant 0.01 ;{ }^{\# \#}: p \leqslant 0.05$. 


\begin{tabular}{|c|c|c|c|}
\hline \multirow[t]{2}{*}{ TABLE 5} & \multicolumn{3}{|c|}{$\begin{array}{l}\text { Multivariate logistic regression analyses in nonatopic children: risk factors associated with wheeze in the previous } 12 \\
\text { months and active asthma\# }\end{array}$} \\
\hline & & Wheeze OR (95\% Cl) & Active asthma OR $(95 \% \mathrm{Cl})$ \\
\hline \multicolumn{2}{|c|}{ Maternal asthma } & $2.8(1.6-5.0)^{+}$ & $5.4(2.5-11.7)^{+}$ \\
\hline \multicolumn{2}{|c|}{ Paternal asthma } & $3.9(2.1-7.5)^{+}$ & $3.3(1.4-7.6)^{+}$ \\
\hline \multicolumn{2}{|c|}{ Bronchiolitis aged $<2$ yrs } & $4.7(2.5-8.9)^{+}$ & $14.5(7.0-30.0)^{+}$ \\
\hline \multicolumn{2}{|c|}{ Maternal smoking } & $1.2(0.8-1.7)$ & $1.0(0.5-1.8)$ \\
\hline \multicolumn{2}{|c|}{ Born before term } & $1.3(0.8-2.3)$ & $0.6(0.2-1.7)$ \\
\hline \multicolumn{2}{|c|}{ Maternal schooling $\geqslant 8$ yrs } & $0.7(0.4-1.1)$ & $0.3(0.1-0.9)^{f}$ \\
\hline \multicolumn{2}{|l|}{$\geqslant 2$ siblings } & $1.1(0.7-1.5)$ & $0.6(0.3-1.05)$ \\
\hline \multicolumn{2}{|c|}{ High-load" Ascaris } & $2.0(1.1-3.8)^{f}$ & $3.1(1.1-6.6)^{f}$ \\
\hline
\end{tabular}

The total number of subjects included in these analyses was 829 . OR: odds ratio; Cl: confidence interval. ${ }^{\#}:$ adjusted for age and sex; ${ }^{\circ}: \geqslant 100$ eggs $\cdot \mathrm{g}^{-1} ;{ }^{+}: \mathrm{p} \leqslant 0.001$; s: $p \leqslant 0.01 ; f: p \leqslant 0.05$.

most wheeze and asthma in these children was not related to atopy. Helminth infection, especially with a higher infective load, increased the risk of wheeze and active asthma, as did attending hospital for acute bronchiolitis during the first 2 yrs of life. Furthermore, in this population, nonatopic asthma was associated with an attenuated form of disease, with less severe or frequent exacerbations compared with atopic asthmatics.

Some authors [15-17] have suggested that the role of atopy in childhood asthma has been overestimated, even in Western countries. The fact that wheeze and asthma-like symptoms are frequently associated with atopy does not imply that these two phenomena are related in the individual child. Longitudinal studies following children from birth [18] and school-age children to adulthood $[19,20]$ have convincingly shown that distinct wheezing phenotypes exist in children. The interaction between genetic susceptibilities and early-life environmental exposures plays a key role in determining the distribution of these wheeze phenotypes in different populations. This is particularly important in relation to early-life infections, especially those due to respiratory viruses, and their profound impact on the recurrence of wheezing during the first decade of life [21, 22].

PEARCE et al. [17] have raised the issue of the role of nonatopic asthma being underestimated in many population studies. The recently published data from the Isle of Wight, UK birth cohort study show that, at the age of $10 \mathrm{yrs}$, the prevalence of atopic and nonatopic wheeze were similar, but that atopic wheezing was more frequently associated with a diagnosis of asthma and treatment for asthma, whereas nonatopic wheeze was more closely associated with recurrent chest infections before the age of 2 yrs [15]. In the present study, the vast majority of wheeze and active asthma at the age of $10 \mathrm{yrs}$ was nonatopic. However, the present population was infected with helminths, which was not the situation in the Isle of Wight study nor in those studies reviewed by PEARCE et al. [17]. When interpreting the present findings, the potential impact of the helminth infections on SPT results for aeroallergens should also be taken into account. Helminth infections and parasite load have been associated with negative SPT results for aeroallergens in a number of studies $[5,8,23]$. Brazilian researchers studying a population chronically infected with Schistosoma mansoni have reported a suppressive effect on SPT results and reduced severity of asthma symptoms [7].

Despite the inverse association of helminth infections and positive SPT results to aeroallergens, it was found that a higher load of Ascaris was a risk factor for asthma and asthma-related symptoms at the age of $10 \mathrm{yrs}$, independent of other common risk factors. This was particularly true when considering nonatopic children in isolation. A similar association has been observed in a large rural population in China [24]. The respiratory effects of Ascaris on the airways may be related to its passage through the lungs during part of its life cycle and its high allergenicity [25]. The clinical symptoms may be associated with Löffler-like syndrome, through either local effects of larval tissue migration, airway reactivity or bronchospasm, infectious bacterial complications of parasitic migration and aspiration or, even more rarely, chronic eosinophilic pneumonia [26]. Helminths may suppress atopic inflammation in the airways, while, at the same time increasing the risk of nonatopic wheeze, possibly via the mechanism outlined above. However, in the absence of serum IgE data, the true effect of helminth infection on atopy remains a matter of speculation.

It is important to take into account the fact that high-Ascaris or high-helminth loads were arbitrarily defined as being values in the upper tertile of the distribution. This corresponded to an infective load of $\geqslant 100 \mathrm{eggs} \cdot \mathrm{g}^{-1}$, which suggests a significant, but far from heavy, infection. Other studies, mainly from rural environments, report a much higher burden of infection than found in the present, rather urbanised, community of Southern Brazil. A protective effect of helminth infection on asthma and allergies may be related to either infective load or frequency of infection rather than simply to the presence of helminths. In many African studies, a protective effect has been shown with hookworm, whereas, in areas in which Ascaris is the most prevalent species, a protective effect may not be found [6]. These differences have been elegantly discussed in the recent meta-analysis of LEONARDI-BEE et al. [6]. However, longitudinal studies are needed in order to adequately investigate whether these apparent helminth-related differences are real and why they occur. 
An important risk factor for asthma reported in many studies is wheezing due to early-life respiratory viral infections [21,27], a variable that has generally not been considered in previous parasite studies. In the present study, bronchiolitis in early life was the strongest risk factor for asthma at the age of 10 yrs. Children with hospital admission or emergency department visits for bronchiolitis before the age of 2 yrs were 17 times more likely to show active asthma, independent of other risk factors. Even more impressive was the finding that subjects with bronchiolitis who were also infected with helminths at the age of 10 yrs were at much greater risk of active asthma. This finding may suggest that this combined exposure (assuming that children infected with Ascaris at the age of 10 yrs have most probably been exposed to these agents since early in life) exerts a major effect on asthma among this mostly nonatopic population through either common or related mechanisms. Bronchiolitis was defined by a specific question answered by mothers due to the cross-sectional nature of the present study. Recall bias or misclassification may play a role here. Although no data are available regarding the agent(s) responsible for bronchiolitis in the present children, it has recently been demonstrated that, in a population with a similar social background, respiratory syncytial virus and rhinovirus were the most common agents associated with wheeze during infancy [28].

In the present study, socioeconomic status was defined by a loose variable, i.e. living in poor neighborhoods, as defined in the original ISAAC phase II protocol. There was a strong correlation between the level of maternal education and place of residence, either in a poor or a better area of town $(R=0.93)$. Although the current authors have no data on healthcare utilisation, there is reason to believe that being infected by helminths is related to not having access to medications, which these children receive on and off, since the major risk factor for these infections is poor hygiene, i.e. lack of a good sanitation structure. This is the case in the city where very few houses have proper sewage and garbage disposal systems in place.

The findings related to the protective factors for asthma and allergies in the proposed hygiene hypothesis must be interpreted with caution in low socioeconomic status environments, such as the one described in the present study. It seems reasonable to assume that some environmental factors exert protective effects by blocking the expression of allergy in populations in which atopic asthma is highly prevalent, and, indeed, environmental factors, such as a higher number of siblings and greater maternal education, were protective against atopy in the present study. However, the most potent environmental exposure reducing the risk of atopy here was infection with intestinal parasites.

In conclusion, the present study shows that asthma and asthma-related symptoms are highly prevalent in the present Brazilian community, in which the majority of the population are of low socioeconomic status. The most prevalent wheeze phenotype in this population was nonatopic. Even though family history of asthma and positive skin-prick test results are significant risk factors for wheezing at the age of $10 \mathrm{yrs}$, the strongest risk factor for persistence of wheeze at this age was bronchiolitis in early life. The present data show that helminth infections can simultaneously induce airway-related symptoms and attenuate atopic disease.

\section{ACKNOWLEDGEMENTS}

The authors would like to thank ALK-Abelló (Madrid, Spain) for donation of the allergens used in the skin-prick testing. The authors would also like to thank C.G. Teixeira for helpful contribution to the methods and analysis of the parasitological testing.

\section{REFERENCES}

1 Burney PG, Chinn S, Rona RJ. Has the prevalence of asthma increased in children? Evidence from the national study of health and growth 1973-86. BMJ 1990; 300: 1306-1310.

2 Sears MR, Herbison GP, Holdaway MD, Hewitt CJ, Flannery EM, Silva PA. The relative risks of sensitivity to grass pollen, house dust mite and cat dander in the development of childhood asthma. Clin Exp Allergy 1989; 19: 419-424.

3 Mensinga TT, Schouten JP, Rijcken B, Weiss ST, Speizer FE, van der Lende $R$. The relationship of eosinophilia and positive skin test reactivity to respiratory symptom prevalence in a community-based population study. J Allergy Clin Immunol 1990; 86: 99-107.

4 Mallol J, Sole D, Asher I, Clayton T, Stein R, Soto-Quiroz M. Prevalence of asthma symptoms in Latin America: the International Study of Asthma and Allergies in Childhood (ISAAC). Pediatr Pulmonol 2000; 30: 439-444.

5 Dagoye D, Bekele Z, Woldemichael K, et al. Wheezing, allergy, and parasite infection in children in urban and rural Ethiopia. Am J Respir Crit Care Med 2003; 167: 1369-1373.

6 Leonardi-Bee J, Pritchard D, Britton J. Asthma and current intestinal parasite infection: systematic review and metaanalysis. Am J Respir Crit Care Med 2006; 174: 514-523.

7 Medeiros M Jr, Figueiredo JP, Almeida MC, et al. Schistosoma mansoni infection is associated with a reduced course of asthma. J Allergy Clin Immunol 2003; 111: 947-951.

8 Cooper PJ, Chico ME, Rodrigues LC, et al. Reduced risk of atopy among school-age children infected with geohelminth parasites in a rural area of the tropics. J Allergy Clin Immunol 2003; 111: 995-1000.

9 Penny ME, Murad S, Madrid SS, et al. Respiratory symptoms, asthma, exercise test spirometry, and atopy in schoolchildren from a Lima shanty town. Thorax 2001; 56: 607-612.

10 Weiland SK, Bjorksten B, Brunekreef B, Cookson WO, von Mutius E, Strachan DP. Phase II of the International Study of Asthma and Allergies in Childhood (ISAAC II): rationale and methods. Eur Respir J 2004; 24: 406-412.

11 Ritchie LS, Lin S, Moon AP, et al. The possible effects of $\mathrm{pH}$ and specific gravity on the ether-sedimentation procedure in concentrating eggs and cysts. Am J Trop Med Hyg 1960; 9: 444-449.

12 Baerman G. Eine einfache Methode zur Auffindung von Ankylostomum-(Nematoden)-Larven in Erdproben. [A simple method for isolation of Ancylostoma (nematode) larvae in soil samples.] Tijdschr Diergeneeskd 1917; 57: 131-137.

13 Katz N, Chaves A, Pellegrino J. A simple device for quantitative stool thick-smear technique in Schistosomiasis mansoni. Rev Inst Med Trop Sao Paulo 1972; 14: 397-400. 
14 ISAAC Phase II Steering Committee. ISAAC Phase II Modules. http://isaac.auckland.ac.nz/Phasetwo/. Date last accessed: March 6, 2007.

15 Kurukulaaratchy RJ, Fenn M, Mathews S, Arshad SH. Characterization of atopic and non-atopic wheeze in 10 year old children. Thorax 2004; 59: 563-568.

16 Beasley R, Pekkanen J, Pearce N. Has the role of atopy in the development of asthma been over-emphasized? Pediatr Pulmonol, 2001: Suppl. 23, 149-150.

17 Pearce N, Pekkanen J, Beasley R. How much asthma is really attributable to atopy? Thorax 1999; 54: 268-272.

18 Martinez FD, Wright AL, Taussig LM, Holberg CJ, Halonen M, Morgan WJ, for The Group Health Medical Associates. Asthma and wheezing in the first six years of life. N Engl J Med 1995; 332: 133-138.

19 Sears MR, Greene JM, Willan AR, et al. A longitudinal, population-based, cohort study of childhood asthma followed to adulthood. N Engl J Med 2003; 349: 1414-1422.

20 Phelan PD, Robertson CF, Olinsky A. The Melbourne Asthma Study: 1964-1999. J Allergy Clin Immunol 2002; 109: 189-194.

21 Stein RT, Sherrill D, Morgan WJ, et al. Respiratory syncytial virus in early life and risk of wheeze and allergy by age 13. Lancet 1999; 354: 541-545.
22 Sigurs N, Bjarnason R, Sigurbergsson F, Kjellman B. Respiratory syncytial virus bronchiolitis in infancy is an important risk factor for asthma and allergy at age 7. Am J Respir Crit Care Med 2000; 161: 1501-1507.

23 Medeiros M Jr, Almeida MC, Figueiredo JP, et al. Low frequency of positive skin tests in asthmatic patients infected with Schistosoma mansoni exposed to high levels of mite allergens. Pediatr Allergy Immunol 2004; 15: 142-147.

24 Palmer LJ, Celedon JC, Weiss ST, Wang B, Fang Z, Xu X Ascaris lumbricoides infection is associated with increased risk of childhood asthma and atopy in rural China. Am J Respir Crit Care Med 2002; 165: 1489-1493.

25 Stoten A, Huntley J, Mistry H, et al. Nonatopic allergenindependent mast cell activation in parasitized eosinophilic athymic rats. Parasite Immunol 2005; 27: 431-438.

26 Sarinas PS, Chitkara RK. Ascariasis and hookworm. Semin Respir Infect 1997; 12: 130-137.

27 Sigurs N, Gustafsson PM, Bjarnason R, et al. Severe respiratory syncytial virus bronchiolitis in infancy and asthma and allergy at age 13. Am J Respir Crit Care Med 2005; 171: 137-141.

28 Pitrez PM, Stein RT, Stuermer L, et al. Bronquiolite aguda por rinovírus em lactentes jovens. [Rhinovirus and acute bronchiolitis in young infants.] J Pediatr (Rio J) 2005; 81: 417-420. 